\title{
Creation of an evidence-based practice reference model in falls prevention: findings from occupational therapy
}

\section{Aliki Thomas, Alenoush Saroyan \& Susanne P. Lajoie}

To cite this article: Aliki Thomas, Alenoush Saroyan \& Susanne P. Lajoie (2012) Creation of an evidence-based practice reference model in falls prevention: findings from occupational therapy, Disability and Rehabilitation, 34:4, 311-328, DOI: $10.3109 / 09638288.2011 .607210$

To link to this article: https://doi.org/10.3109/09638288.2011.607210

Published online: 12 Oct 2011.

Submit your article to this journal $\sqsubset$

Џ Article views: 937

Q View related articles $\square$

Citing articles: 3 View citing articles 4 


\title{
Creation of an evidence-based practice reference model in falls prevention: findings from occupational therapy
}

\author{
Aliki Thomas $\mathrm{PhD}^{1,2}$, Alenoush Saroyan $\mathrm{PhD}^{1}$ \& Susanne P. Lajoie $\mathrm{PhD}^{1}$ \\ ${ }^{1}$ Department of Educational and Counselling Psychology, McGill University, Montreal, Quebec, Canada and ${ }^{2}$ School of Physical \\ and Occupational Therapy, Faculty of Medicine, McGill University, Montreal, Quebec, Canada
}

Purpose: This study attempted to capture the evidence-based practice (EBP) behaviours of expert occupational therapy (OT) clinicians in order to develop a reference model of EBP in falls prevention. Methods: Expert clinicians participated in the creation of a clinical vignette through focus group discussions. Using the vignette as the stimulus case, the same clinicians answered questions that reflected the EBP process. Validation of original responses and data synthesis occurred through a second focus group. This validation process resulted in the elaboration of a tree structure EBP decision model. Results: Findings show that clinicians are not expert evidence-based practitioners. Although some of the experts' clinical decisions were based on a combination of professional experience and research evidence, clinicians relied primarily on clinical experience for more complex aspects of decision-making. When explicitly instructed to answer questions corresponding to the five EBP steps, experts were compelled to think about the use of evidence and could proceed through the EBP process. Conclusions: The model represents the expert clinical decisions in each of the EBP steps and illustrates what aspects of the decision-making process are in line with EBP versus aspects that are driven primarily by experience. This research has the potential to assist clinicians working in prevention of falls in geriatric rehabilitation who can use the model as a practice framework to guide them through the EBP process.

Keywords: Occupational therapy, evidence-based practice, falls, professional practice

\section{Introduction}

With advances in rehabilitation interventions and rising expectations from consumers to receive best possible care, occupational therapists (OTs) are expected to work within an evidence-based practice (EBP) context [1-3]. There is good evidence that findings from scientific research are not routinely used to inform decisions about patient care [4-7].

\section{Implications for Rehabilitation}

- Experienced clinicians can proceed through the steps of the evidence-based practice process with guidance and scaffolding.

- Clinical experience is a major factor in decisionmaking in falls prevention.

- Models of expert performance provide useful insights into decision-making outcomes and evidence-based practise behaviours of experienced clinicians in falls prevention.

In fact, although there has been a rise in available scientific evidence in areas of occupational therapy (OT) such as stroke and cerebral palsy, many clinicians continue to use practices that are not supported by this research. As a result, researchers are now shifting their focus towards identifying and applying effective strategies to help clinicians embrace and adopt EBP. To support clinicians in this endeavour, a clearer understanding of what characterizes optimal performance in an evidence-based decision-making approach is needed. Attributes of expert performance gleaned from observations of clinicians who apply EBP in their daily practice can provide useful insights into what expert EBP looks like in a particular clinical area. These attributes can then be used to design models of EBP that present clinicians with a framework for best practice. Expert models can also be useful for educators in the design of curricula that help students acquire EBP competencies $[8,9]$. Although falls in the elderly is a growing problem with substantial resources being allocated for prevention and management of patients with falls and that there is a large body of scientific evidence on fall prevention strategies, there is no empirical evidence on the behaviours and decisions of expert OT clinicians who apply the EBP process in this area of practice. This paper describes the process of generating an OT reference model 
of EBP behaviours in the area of prevention of falls in the elderly population and the resulting tree structured decision model.

\section{Background}

Evidence-based practice (EBP) has been defined as the integration of current best evidence with clinical expertise and patient choice [10]. EBP involves a five-step process [11-13]: 1) formulating a clear and answerable question derived from the patient's problem or need, that captures four components: (P) the target population, (I) the intervention, (C) the comparison to another group or another intervention and $(\mathrm{O})$ the desired outcome of the intervention; 2) searching the literature for the best available research to help answer the clinical (PICO) question; 3) conducting a critical appraisal of the literature to assess its trustworthiness and its value and relevance for a particular patient and context; 4) combining clinical expertise, the patient's perspective and the available scientific evidence in making a clinical decision for and 5) assessing the effectiveness of the intervention and one's proficiency with the EBP process.

Mounting interest in EBP for its potential to improve patient outcomes and efforts to help clinicians adopt EBP have led to a burgeoning of research on various aspects of this process. These include monitoring of gaps between actual practice and EBP, identification of EBP barriers and the role of experience and expertise in the application of research evidence in clinical practice.

\section{Gaps between actual practice and EBP}

While the EBP process has been clearly delineated and OT clinicians are frequently reminded of the importance of basing their clinical decisions on scientific evidence, several studies have found that OTs are not incorporating research findings in their practice [4-7]. Researchers in the USA [4,7] surveyed OTs to examine the use of evidence in practice and found that although the majority of therapists had favourable attitudes towards EBP and felt that EBP should be an essential part of clinical practice, only $38 \%$ of surveyed clinicians reported using research findings in their practice [7]. Likewise, a survey of 930 US therapists showed that while most (97\%) had positive attitudes about EBP and close to $80 \%$ were confident in their ability to find and critically review the literature, only one in four therapists actually used the literature to inform their clinical decision-making [5]. A cross Canada study on stroke rehabilitation [6] found that clinicians were not routinely using best practices even though there are over 900 randomized controlled trials on assessment and treatment interventions in stroke management and many readily available and highly recognized best practice guidelines $[14,15]$. Also in the area of stroke, a multi-center study of rehabilitation specialists [16] found that only $13 \%$ of patients with unilateral spatial neglect were actually assessed with a standardized assessment; an intervention that is consistent with EBP. Results from these studies clearly highlight the substantial gap that exists between the norms of EBP and current OT practice.

\section{Barriers to EBP}

Poor uptake of research findings in OT practice has been found to be in large part due to a number of barriers including a lack of administrative support (limited access to research materials, computers and library resources) [17], a lack of dedicated time to search for and incorporate research results in practice $[4,6,18,19]$, negative attitudes towards research [20] and a lack of confidence and skill in interpreting, synthesizing and applying research findings [18,21-25]. A more recent study on factors that influence clinicians in adopting best practice suggests that personal habits may also block clinicians from adopting sound practices [26].

For EBP to be successfully employed and to improve patient outcomes, practitioners must be able to combine their clinical expertise with the best available evidence from research as well as with the values and preferences of the patient they are interacting with. It appears that the extent to which research findings can actually inform clinical practice is related to not only the factors listed above but to both clinical expertise and experience [27-31]. Research evidence is only one element of EBP. It is not a substitute for clinical judgment nor does it contribute to EBP in isolation $[1,29,32]$.

\section{The role of experience and expertise in EBP}

Although the literature on EBP expertise is primarily anecdotal, there is extensive research on expertise in general and expertise in the professions in particular, that offers a solid foundation for identifying and understanding expertise in EBP. This literature can be useful in informing the development of OT expert models and outlining what individual OTs need to know along a trajectory of development, to demonstrate complex performance in a given domain such as EBP $[8,9,34,35]$.

Traditional expertise research has shown that experts reach superior performance levels in their domain not only because of years of experience but because of deliberate practice. This form of practice involves self-monitoring as well as feedback on well-defined tasks that help the individuals improve certain aspects of their performance [36-39]. In the context of solving problems, experts are better than novices at retrieving and using large amounts of well-organized and structured domain-specific knowledge [40-42] and they do so with minimal cognitive effort [8]. They execute skills with greater automaticity, exert greater cognitive control of their performance [43] and readily use all sources of information and available resources in order to solve a problem [44]. Experts are attuned to a problem's affordances, utilizing these to solve problems more effectively [45]. They focus on conceptual features of a problem and see patterns, cues and underlying principles $[42,46]$, they can select better problem solving strategies and they deal with both well and ill-defined problems more successfully than novices $[40,42,43,46,47]$. Although initially experts spend more time analyzing an unfamiliar problem qualitatively, they are faster at solving the problem because of extended practice in the domain, highly developed pattern recognition and more efficient problem solving skills $[48,49]$. Moreover, experts have better self-monitoring abilities which help them detect errors and remain informed about the status of their comprehension as they solve a problem [50,51]. 


\section{Expertise in the health professions}

Findings from expertise studies in medicine [52-58], nursing [59-64] and psychology [65] have formed the foundation for our current understanding of expertise in the health professions and its distinguishing attributes from expertise in other domains such as music, chess and sports. Expertise in medicine and OT is unlike expertise in many other domains [66] in that these experts demonstrate mastery of a diverse body of knowledge (biomedical, clinical) and a range of motor (surgical skills, manual muscle testing skills), cognitive (problem solving, clinical reasoning) and interpersonal skills. Also unlike other domains, expertise in the health professions involves coordination of formal versus experiential knowledge. For instance, physicians must keep up with the volume of new knowledge on diagnostic tools and medical treatments [67] in addition to engaging in extensive periods of professional development and deliberate practice in order to attain success in their domain.

The major common features of expertise that cut across different domains and makes it different from more generic skills or talents, be it in medicine, sport or chess, is the breadth and depth of individuals' knowledge, their highly developed cognitive processes and their engagement in extensive and deliberate practice with feedback [66].

\section{Who qualifies as an expert?}

Identifying someone as an expert in their domain has always been a contentious issue in studies of expertise [36,41,68-70]. Criteria used to identify someone as an expert in a domain include social reputation (peer nomination), formal education, accumulated accessible knowledge and length of experience in a domain, which is typically over 10 years [34,71]. Critics have been particularly vocal about using social reputation and length of experience as criteria. In fact, in the case of peer nomination of experts in computer programming [72] and physics [73], actual performance of the nominated experts using this criterion was found to be not exceptional at all. The performance of both computer programmers and physics professors were not consistently superior to that of computer science students or physics students' performance on introductory physics problems. With regards to using the level of training and experience as a criterion for identifying experts, it has been suggested that often, this attribute has only a "weak link to objective measures of performance" [43]. Studies in psychology [74], software design [75], finance [76] and medicine [39] have shown that length of experience and training are not consistently associated with success in patient care, superior financial advice on investments and more accurate diagnoses of heart sounds. As a result, rather than use the above-mentioned criteria, researchers have proposed that the focus be shifted to identifying individuals who consistently perform in a superior manner in a specific area, whether they are socially recognized as experts or not [39]. To establish the quality of performance, typically laboratory tasks (think aloud, recall and summarization, explanation and knowledge elicitation) have been used both in general studies of expertise and expertise in biomedical domains [77,78].

While there is a need for OTs to offer evidence-based services, research findings suggest that available scientific evidence is not routinely used to inform clinical decisions. Features of expertise in OT have yet to be studied in relation to the behaviours and skills reflected in EBP. In other words, it is not clear if and how expert OT clinicians manifest EBP. Supporting clinicians in successfully integrating evidence in practice requires a thorough understanding of how attributes and behaviours of expert OT clinicians in a given context correspond with the EBP process. This study aimed to identify the practice behaviours of expert OT clinicians in prevention of falls in the geriatric population, determine the extent to which these are congruent with EBP and use the identified behaviours to create an EBP reference model for OT practitioners.

\section{Methods}

Ethics approval was obtained from the Institutional Review Board of the Faculty of Medicine of a research intensive University, in Montreal, Quebec, Canada.

\section{Study participants \\ Recruitment}

Study participants were expert OTs from five University affiliated clinical sites in a large metropolitan area in Quebec, Canada. Taking into account common practice and the corresponding criticisms regarding the criteria for identifying experts, for the purposes of this study, for participants to be considered expert, they had to meet the following criteria: 1) be nominated by the OT department manager who had to consider the person an expert in geriatrics and vouch for their ongoing participation in falls prevention programs; 2 ) have 10 or more years of OT clinical experience in geriatrics; 3 ) have participated in a minimum of one falls prevention activity per year and 4) be willing to provide informed consent. To recruit participants, the principal investigator contacted the OT manager at five clinical sites in the metropolitan area of the study, described the study and asked for names of clinicians who met the inclusion criteria. Ten clinicians met the study criteria. Subsequently, a letter including the description of the study and the invitation to participate along with a consent form were sent to these individuals. The invitation resulted in nine respondents who comprised the expert OT sample and agreed to take part in study.

\section{Participant characteristics}

Table I shows participants' professional employment and clinical experience profile. One participant worked in a long term care facility, four were employed in geriatric rehabilitation centers, three worked in an adult rehabilitation center where the majority of patients are over the age of 65 and one clinician worked in the community where the majority of her interventions took place in patients' homes.

\section{Study procedure}

There were three phases in the creation of the OT EBP reference model. Phase 1 involved designing a clinical vignette to be used as the stimulus case for capturing the EBP process of study participants. Vignettes have been used for eliciting clinicians' attitudes and beliefs, evaluating recall, applying 
Table I. Characteristics of the nine (9) participating expert occupational therapists.

\begin{tabular}{|c|c|}
\hline \multirow[t]{4}{*}{ Practice area } & Long term care: $(n=1)$ \\
\hline & Geriatric rehabilitation: $(n=4)$ \\
\hline & Adult rehabilitation: $(n=3)$ \\
\hline & Community: $(n=1)$ \\
\hline Experience in OT & 18 (range: $10-30$ ) \\
\hline Experience in geriatrics & 16 (range: 9-20) \\
\hline Experience in falls prevention & 16 (range: 9-20) \\
\hline \multirow[t]{3}{*}{ Previous degrees } & Yes $=2$ \\
\hline & $\begin{array}{l}\text { Diploma in organizational } \\
\text { micromanagement }\end{array}$ \\
\hline & Diploma in management (in progress) \\
\hline \multirow{8}{*}{$\begin{array}{l}\text { Participation in the } \\
\text { development of fall } \\
\text { prevention initiatives }\end{array}$} & Yes $n=6$ \\
\hline & Nature of fall prevention initiatives \\
\hline & $\begin{array}{l}\text { 1) Development of policies and procedures } \\
\text { regarding falls prevention in OT and PT } \\
\text { and alternatives to restrains }\end{array}$ \\
\hline & $\begin{array}{l}\text { 2) Development measures for preventing } \\
\text { falls including risk for falls scale }\end{array}$ \\
\hline & $\begin{array}{l}\text { 3) Group education sessions for clients and } \\
\text { families }\end{array}$ \\
\hline & $\begin{array}{l}\text { 4) Education in the community about falls } \\
\text { and falls prevention }\end{array}$ \\
\hline & $\begin{array}{l}\text { 5) Development of an education module } \\
\text { for clients in hospital }\end{array}$ \\
\hline & $\begin{array}{l}\text { 6) Development of a one hour fall } \\
\text { prevention session for clients in hospital }\end{array}$ \\
\hline \multirow[t]{5}{*}{$\begin{array}{l}\text { Frequency of participation in } \\
\text { falls prevention programs }\end{array}$} & $\begin{array}{l}\text { Minimally at present time }(n=2) \\
\text { Daily }(n=1)\end{array}$ \\
\hline & Weekly $(n=1)$ \\
\hline & Monthly $(n=1)$ \\
\hline & Bi-monthly $(n=2)$ \\
\hline & As needed $(n=2)$ \\
\hline
\end{tabular}

clinical knowledge to solving clinical problems [79-81] and elucidating the OT decision-making process [82]. Clinical vignettes, contrary to actual clinical case data, afford the possibility of including as much detail as necessary depending on the nature of the information being elicited, the learning task and the level of the learner. Clinical vignettes can also be used in educational contexts as learning tools to help students identify core clinical features and begin to work through the EBP process. The practice area, 'prevention of falls in the geriatric population', was selected for three reasons: 1) Falls are a serious and prevalent problem in the elderly. Substantial human and financial resources are often allocated to deal with this serious problem; 2) OTs have a key role in falls prevention programs as well as in the follow-up of patients with repeated falls; 3) Unlike many other areas of OT practice there is considerable scientific research available that can be used to inform clinical practice and facilitate EBP.

Study participants attended a two-hour focus group to discuss the content of a vignette depicting an elderly patient with a history of falls who is admitted to a hospital that is specializing in geriatric rehabilitation for OT assessment and treatment. The focus group used a dual moderator format [83]. The moderator (AT) asked open-ended questions and used probes to guide participants through the discussion. The experienced co-moderator, who was familiar with the area of
Table II. First focus group questions.

1. What kind of client would you commonly see in a clinical setting who has been admitted due to a fall (age, gender, reason for admission)?

2. What would be a realistic past medical history?

3. What kind of social history would you expect this client to have?

4. What would be the circumstances surrounding the fall?

5. What would be the clinical profile upon admission?

6. What medical treatment/ interventions would be done in acute care immediately following the fall?

7. What would be the documented reason for referral to OT?

8. What would be the assessment process in OT?

9. What results would you anticipate from the OT assessment?

10. What would the OT treatment plan be?

11. What recommendations would be made regarding and prior to discharge?

12. What would you anticipate the client's overall status to be at discharge?

study but was not part of the research team, ensured that the session progressed smoothly. The discussion was framed with 12 questions (Table II). Two research assistants took detailed notes during the focus group. The moderator transcribed the notes into a coherent clinical vignette which was then sent to the nine clinicians for member checking [84]. No revisions or additions were proposed. The outcome of this phase was a clinical vignette depicting an elderly woman with a history of falls (Appendix A).

Phase 2 involved applying the EBP process as the expert clinicians dealt with the patient presented in the vignette. Table III shows the five questions corresponding to the EBP steps that participants were asked to answer. The final vignette and the five EBP questions were mailed to the participants. To ensure that participants had sufficient time to complete the questions given their busy schedules, they were given eight weeks to respond individually. They were instructed to use any information or resources at their disposal, other than peers or superiors. No specific instructions were provided on the nature of the information to be included. There was no reference to the EBP process and neither was there a glossary to provide definitions for various terms. Participants requested an extension to complete the task and were granted four additional weeks. At the end of the 12 week-period, one participant did not complete the task and another withdrew from the study. This resulted in a sample of seven experts completing the study.

In Phase 3, following a preliminary analysis (described in detailed in the next section) of the data generated by clinicians' original responses to the questions listed in Table III, the seven participating clinicians were invited to a second focus group. This consensus building exercise allowed for the verification of data, analytic categories and interpretations with participants from whom the data were originally obtained $[85,86]$ and allowed for greater synthesis of the responses generated in phase 2. This member checking focus group also enhanced the validity of interpretations made during all phases of the analysis. Five of the seven original clinicians participated in this focus group, and as a group, they added, deleted or modified responses and selected the ideal answer for each question. 
Table III. Questions regarding EBP process.

\begin{tabular}{|c|c|}
\hline EBP step & Question \\
\hline $\begin{array}{l}\text { Step 1: Clinical } \\
\text { Question }\end{array}$ & $\begin{array}{l}\text { Given the scenario in the vignette and the family's } \\
\text { question regarding the fall prevention program, } \\
\text { what is your PICO question for this client? }\end{array}$ \\
\hline $\begin{array}{l}\text { Step 2: Searching } \\
\text { the Literature }\end{array}$ & $\begin{array}{l}\text { Conduct a search to find literature that could help } \\
\text { you answer your PICO question.As part of your } \\
\text { search strategy list which databases, search engines } \\
\text { and key words you would use? Once you identify the } \\
\text { sources, which of the following factors do you use } \\
\text { to determine the value of the source: peer-reviewed } \\
\text { sources, type of publication and research design, } \\
\text { type of scholarly databases, disciplinary source and } \\
\text { impact factor. Rate each factor as 'must drive my } \\
\text { search', 'can drive my search', 'does not drive my } \\
\text { search' or 'do not know'. }\end{array}$ \\
\hline $\begin{array}{l}\text { Step 3: Appraising } \\
\text { the Literature }\end{array}$ & $\begin{array}{l}\text { Appraise the literature you found in relation to the } \\
\text { client in the vignette.In critically appraising the } \\
\text { literature, list and rank, in order of importance, } \\
\text { the sections of an article you consider most useful? } \\
\text { (Example: abstract, methods, discussion, results, etc.) }\end{array}$ \\
\hline $\begin{array}{l}\text { Step 4: Decision- } \\
\text { making }\end{array}$ & $\begin{array}{l}\text { What will you recommend for this client?Describe } \\
\text { your plan/ recommendations and state which } \\
\text { of the EBP components (research evidence, } \\
\text { clinical experience, client wishes) informed your } \\
\text { recommendations. }\end{array}$ \\
\hline Step 5: Re-evaluation & $\begin{array}{l}\text { The client has been home three months after having } \\
\text { completed your recommended fall prevention } \\
\text { program and has fallen twice since the treatment } \\
\text { ended. The client's daughter has contacted you to } \\
\text { let you know about the recent falls. Answer the } \\
\text { following } 3 \text { questions: } \text { List the possible reasons } \\
\text { why the client (Mrs. P.) fell again?. What will you } \\
\text { recommend in this situation?.Which of the EBP } \\
\text { components (research evidence, clinical experience, } \\
\text { client wishes) informed your recommendations. }{ }^{\text {a }}\end{array}$ \\
\hline
\end{tabular}

This hypothetical scenario was provided because participants could not observe the actual outcome of the intervention or objectively evaluate the reasons for the recurrence of falls.

Mediated group discussions led to synthetic categories of concepts and sequence of actions for each EBP step. The final categories and concepts were used to create a tree structure reference model that highlights the expert group's decisions and the sequence in which these would be made for the elderly patient with a history of falls depicted in the simulated scenario.

\section{Data sources, analysis and synthesis}

Participants' written responses to the five EBP questions comprised the data source for this study. Analysis occurred in three levels. First, individual responses were recorded and compiled. Second, the principal investigator (PI) used open and axial coding to generate low inference categories from the original responses [85]. This facilitated the identification of similarities in participant responses when they were describing the same concept or making reference to a similar concept. Third, the categories were further synthesized into categories of what appeared to be similar actions, behaviours or decisions. These analyses accommodated for taking into account both individual and group responses.

Participants were shown the three levels of analysis during the member checking activity. Specifically, the PI showed the original responses, along with levels 2 and 3 of the analysis. The PI explained how the analysis took place and asked participants: 1) whether their responses were included in level 1 ,
Table IV. Analysis of 'P' component of PICO.

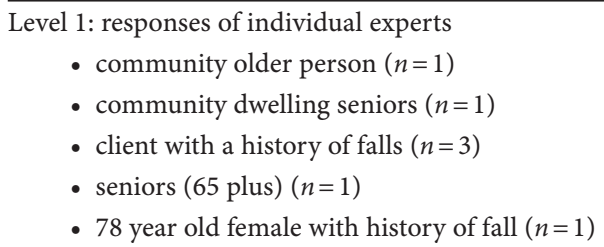

Level 2: response of experts, combined and grounded Expert responses regarding population make reference to:

- person/age/gender: older person, senior, client, senior over 65, 78 year old female

- reference to location of residence: community, community dwelling

- condition or client characteristic/history: history of falls

Level 3: synthesis: possible combinations of concepts and words to be used in the "P" of the PICO

- for an older client/ for a senior/ for a client/for a senior over $65 /$ for older women

- for an older person living in the community/for a senior living in the community/ for a client living in the community/ for a senior over 65 living in the community/ for older women living in the community

- for a community dwelling older person/ for a community dwelling senior/ for a community dwelling client/ for a community dwelling senior over $65 /$ for community dwelling older women

- for an older person living in the community with a history of falls/ for a senior living in the community with a history of falls/ for a client living in the community with a history of falls/ for a senior over 65 with a history of falls living in the community/ for elderly women with a history of falls living in the community

2) whether their original responses were reflected in levels 2 , 3 ) whether they agreed with the categories and concepts generated from the coding process and 4) whether they wished to add or remove any of the categories and concepts. Group discussions ensued for each EBP question. Consensus was achieved on the three levels of analysis for each EBP step. This three-step process of analysis is elaborated below using the first question as an example.

\section{EBP Step 1: PICO question (Tables IV-VII)}

For the first question (EBP Step 1), participants presented their PICO questions. The PI identified the four PICO components for each participant.

Analysis level 1: Table IV illustrates the analysis of the population (P) component of the PICO which involved a list and frequency of responses. Responses included: "community older person", "community dwelling senior", "patient with a history of falls", "senior over 65 " and "78 year old female with a history of fall".

Analysis level 2: Open and axial coding was used to identify categories and their associated concepts. The coding resulted in three categories for the "P": a) person/age/ gender, b) location of residence and c) condition/patient characteristic. Nested within each category were a number of concepts. "Older person", "senior", "patient", "senior over 65 " and "78 year old female" were concepts nested within the first category person/age/gender. The concepts "community" and "community dwelling" were nested within the second category and the concept "history of falls" was nested within the category condition/patient characteristic. 
Table V. Analysis of 'I' component of PICO.

Level 1: responses of individual experts

- participation in a rehabilitation usual rehabilitation care and multifactor fall prevention program $(n=1)$

- the evidence for the value of fall prevention programs $(n=1)$

- participation in a fall prevention program in the community $(n=3)$

- a fall prevention session $(n=1)$

- no intervention $(n=1)$

Level 2: response of experts, combined responses grounded (with range of responses) Responses regarding the intervention make reference to:

- program only: fall prevention programs

- a session not full program: session

- location of the program (where the program would take place): fall prevention program $\underline{\text { in the community }}$

- program type in combination with rehabilitation (traditional rehabilitation): a rehabilitation usual rehabilitation care and multifactor fall prevention program

Level 3: synthesis: possible permutations

- fall prevention session

- fall prevention program

- fall prevention program in the community

- multifactorial fall prevention session

- multifactorial fall prevention session in the community

- multifactorial fall prevention in the community

- multifactorial fall prevention program and usual rehabilitation

Table VI. Analysis of 'C' component of PICO.

Level 1: response of individual expert

- usual rehabilitation care with no participation to fall prevention program $(n=1)$

- compared to only having exposure to OT and PT on the ward during hospitalization $(n=3)$

- in comparison to seniors who do not have access to this kind of session $(n=1)$

- no comparison $(n=1)$

Level 2: response of experts, combined responses grounded (with range of responses) Responses regarding comparison make reference to:

- comparing the intervention with traditional rehabilitation only (usual rehabilitation, exposure to PT and OT only)

- comparing the intervention with no intervention (do not have access to this kind of session)

- location of the program/where the program would take place: while in hospital, in client)

Level 3 synthesis: possible permutations

- compared to traditional PT and OT only

- compared to usual rehabilitation only

- compared to those who do to have access to this session

- compared to usual in client rehabilitation only

Analysis level 3: The final step in data reduction involved combining the low inference categories into themes representing all the possible variations of actions, behaviours or decisions. Table IV illustrates the 20 possible variations for the ' $\mathrm{P}$ '. These were increasingly detailed ranging from a simple "For an older patient" to a more detailed description such as "for a senior over 65 with a history of falls living in the community". During the member checking activity, participants were presented with the three levels of analysis and asked to agree upon which categories and specific words described each PICO component. Tables V-VII show the analysis for
Table VII. Analysis of 'O' component of PICO.

Level 1: response of individual expert

- reduce the incidence of fall $(n=1)$

- in minimizing falls and their effects $(n=1)$

- decrease the number of future falls $(n=3)$

- decrease the number of falls or the severity of injury $(n=1)$

- no outcome $(n=1)$

Level 2: response of experts, combined responses grounded (with range of responses) Responses regarding outcome make reference to:

- reduction in incidence/ number of falls (\# of falls)

- reduction in incidence/ number and effects of falls (\# of falls + effects)

- reduction in incidence/ number or severity of injury (\# of falls + / or effects)

- subsequent falls (falls in the future) (timing of falls)

Level 3 synthesis: possible permutations

- reduce the number of falls

- reduce the number of falls and their effects

- reduce the number of falls or the severity of falls

- reduce the number of falls in the future

- reduce the number of future falls and their effects

- reduce the number of future falls or the severity of their effects

the remaining three components of the PICO question. The same analysis was carried out for steps 2, 3, 4 and 5 of the EBP process.

\section{Results}

\section{EBP model step 1: PICO question}

Figure 1 illustrates the results generated from Step 1 in a schematic format. Fourteen categories representing the four PICO components were identified. For example the 'population' component includes three categories (person, location, condition/patient characteristic). Nested within each category are a number of concepts. Concepts represent either a synonym or an alternative for a PICO concept. For example in the category 'person' the concepts "older person", "senior", "patient", "senior over 65 " are synonyms used to describe the individual in the vignette. In the category 'another intervention' the concepts "traditional rehabilitation" and "PT and OT only" represent two different intervention alternatives.

The highlighted terms in Figure 1 represent the final concepts that make up the PICO question for the patient in the vignette as per participant consensus: $(P)$ For a senior over the age of 65 with a history of falls and living in the community, (I) does participation in a multifactorial fall prevention program in addition to traditional rehabilitation, $(O)$ reduce the number of future falls and the need for hospitalization, (C) compared to traditional in patient rehabilitation only?

\section{EBP model step 2: searching the literature Results of literature search}

Participants identified 33 articles from 20 different sources (Table VIII). Eighty percent $(n=16)$ of the sources were peer reviewed journals, $60 \%(n=12)$ of which had an impact factor. Eighty percent $(n=16)$ were from health care disciplines other than occupational therapy or physical therapy and two of these (10\%) were from peer reviewed rehabilitation journals. Thirty 


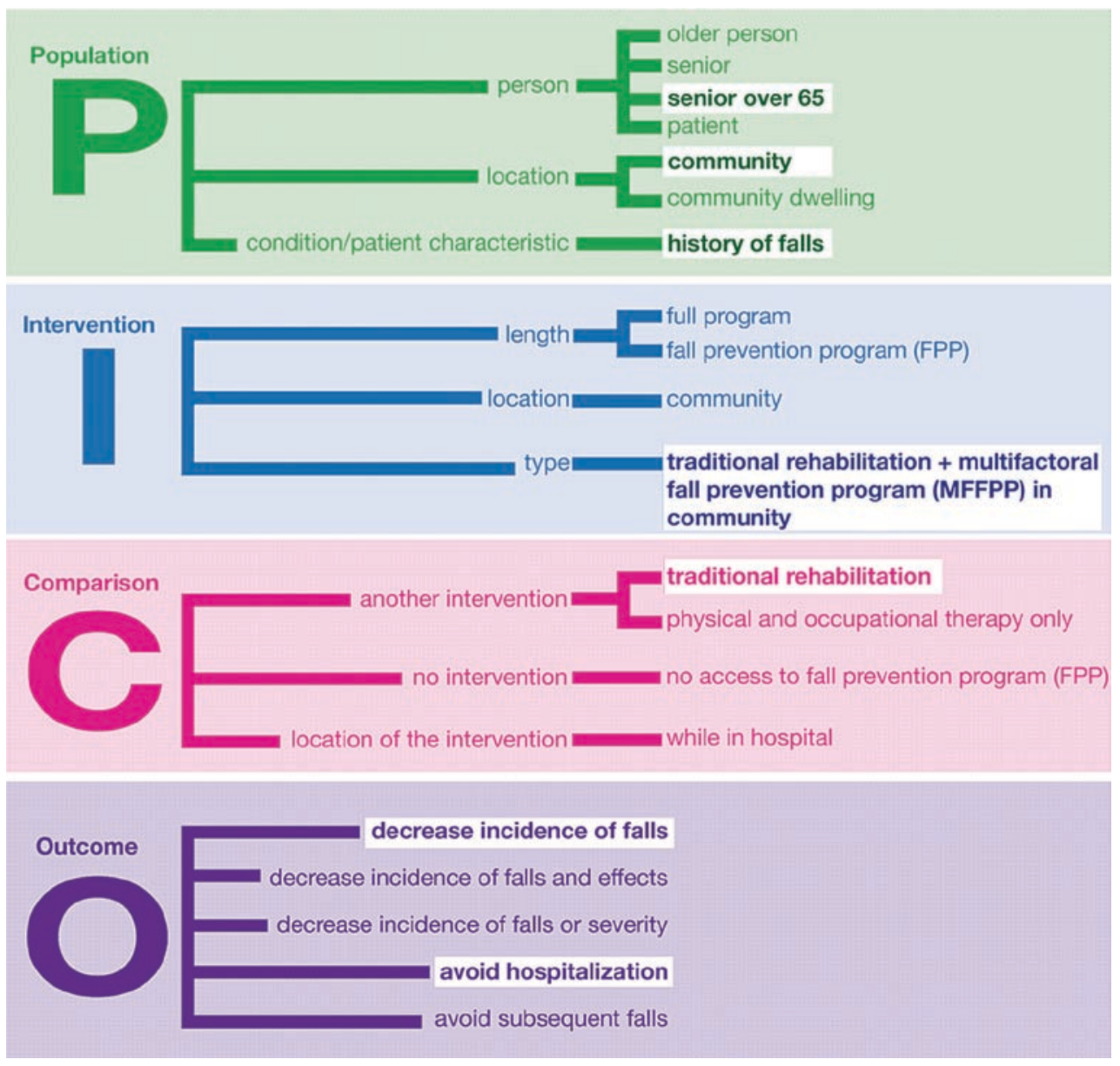

Figure 1. EBP reference model step 1: clinical (PICO) question.

six percent (12/33) of the articles reported results of randomized controlled trials, four were systematic reviews (12\%) and two (6\%) were meta-analyses. Since the reference model in this study primarily represents processes, these results were not included in the representation.

The tree structure for searching the literature is illustrated in Figure 2. It includes participants' ratings of the five 'driving factors' (peer-review, research design, databases, disciplinary sources and journal impact factor) and the five categories of key words used in searching the literature. 'Peer-reviewed source' is the only factor rated as 'must drive the search'. The categories of key words include 'person', 'prevention', 'benefits', 'intervention' and 'location'. Nested within the categories, are the specific keywords used for search. For the category 'person', participants identified six keywords (concepts): "elderly", "over 65 years of age with history of falls", "older", "senior", "falls in the elderly" and "over 65". Rankings of the keywords are illustrated with the numbers, 1,2 and 3 . No ranking indicates that the keywords can be used interchangeably if the original search (using the first three keywords) fails to produce relevant literature.

\section{EBP model step 3: critical appraisal}

The information gleaned from this step was limited because only two of the seven participants answered the question. There was no evidence of formal critical appraisal although one of the two participants who answered this question used recognized critical appraisal criteria such as 'supportive of PICO', 'similarity of study populations', 'sample size', 'quality of results regarding the effectiveness of the intervention' and the use of randomized controlled trials as a rigorous research design'. Figure 3 shows the four main critical appraisal categories and accompanying concepts that were derived from the consensus building focus group: 'standard of the research' (of high standard, of low standard), 'relevance of the research', 'usefulness of the research' and 'manuscript sections'. For example, a study was deemed to be of a "high standard" (category) if it was "supportive of the PICO question" (concept) and if the study findings showed the intervention to be effective (concept). Figure 3 also illustrates which of the manuscript sections and subsections were considered to be important when reading the literature and the corresponding rating for each. In the 'methods' category for example, participants reported that they 'must read' about "study variables", "sample size", "description of the intervention", "outcomes measures", "research instruments" and "research design". They do not read about the "setting" in which the study was conducted. Depending on the circumstances, they 'can read' about "inclusion and exclusion criteria" as well as "statistics" and "data analysis". Participants disregarded this information in clinical decision making because of a self-reported lack of knowledge in these areas. 
Table VIII. Results from searches.

\begin{tabular}{|c|c|c|c|c|c|}
\hline Journal/source & Study design $(\mathrm{n})$ & $\begin{array}{l}\text { Total } n \text { of articles from } \\
\text { source }\end{array}$ & Peer-reviewed source & Impact factor & $\begin{array}{l}\text { Disciplinary source: PT/ } \\
\text { OT Other health disciplines } \\
\text { (OHD), Other }(\mathrm{O})\end{array}$ \\
\hline $\begin{array}{l}\text { Journal of Science and Medicine } \\
\text { in Sport }\end{array}$ & review & 1 & Yes & Yes: 1.212 & OHD \\
\hline Age and Ageing & $\begin{array}{l}\text { letter to the editor } \\
\text { (1) MA (1) }\end{array}$ & 2 & Yes & Yes: 1.910 & OHD \\
\hline Gerontology & review (1) & 1 & Yes & Yes: 1.358 & $\mathrm{OHD}$ \\
\hline $\begin{array}{l}\text { Journal of American Geriatrics } \\
\text { Society }\end{array}$ & review (1) RCT (6) & 7 & Yes & Yes: 3.539 & $\mathrm{OHD}$ \\
\hline $\begin{array}{l}\text { Worldviews on Evidence Based } \\
\text { Nursing }\end{array}$ & SR (1) & 1 & Yes & Yes: 1.167 & $\mathrm{OHD}$ \\
\hline Cochrane Library 2009 & SR (1) & 1 & N/A & N/A & OHD \\
\hline British Medical Journal & RCT (1) SR (1) & 2 & Yes & Yes: 9.723 & OHD \\
\hline $\begin{array}{l}\text { Australian Occupational Therapy } \\
\text { Journal }\end{array}$ & SR (1) & 1 & Yes & No & $\mathrm{PT} / \mathrm{OT}$ \\
\hline $\begin{array}{l}\text { Canadian Seating and mobility } \\
\text { conference Proceedings }\end{array}$ & $\begin{array}{l}\text { conference } \\
\text { proceedings }\end{array}$ & 1 & No & N/A & $\mathrm{O}$ \\
\hline Journal of Gerontological Nursing & pilot study & 1 & Yes & No & OHD \\
\hline $\begin{array}{l}\text { Report Public Health agency of } \\
\text { Canada }\end{array}$ & technical report & 1 & No & No & Other \\
\hline Nursing and Health Sciences. & $\begin{array}{l}\text { clinical trail non- } \\
\text { randomized (1) }\end{array}$ & 1 & Yes & No & OHD \\
\hline Clinical Calcium & $?$ & 1 & $?$ & No & $\mathrm{OHD}$ \\
\hline Physical Therapy. & $\begin{array}{l}\text { longitudinal cohort } \\
\text { study (1) Cross } \\
\text { sectional survey } \\
\text { (1) RCT (1) }\end{array}$ & 3 & Yes & No & $\mathrm{PT} / \mathrm{OT}$ \\
\hline New England Journal of Medicine & $\begin{array}{l}\text { Review (1) } \\
\text { Clinical trial (1) } \\
\text { Prospective study } \\
\text { (1) }\end{array}$ & 3 & Yes & Yes: 51 & $\mathrm{OHD}$ \\
\hline $\begin{array}{l}\text { Journal of Epidemiology and } \\
\text { community health }\end{array}$ & RCT (1) & 1 & Yes & Yes: 2.956 & OHD \\
\hline Gerontologist. & RCT (1) & 1 & Yes & Yes: 1.820 & OHD \\
\hline Medical Care & RCT (1) & 1 & Yes & Yes: 3.534 & OHD \\
\hline $\begin{array}{l}\text { Journal of the American Medical } \\
\text { Association }\end{array}$ & $\mathrm{MA}(1)$ & 2 & Yes & Yes: 23.17 & OHD \\
\hline American Journal of Medicine & RCT (1) & 1 & Yes & Yes: 4.907 & OHD \\
\hline \multirow[t]{4}{*}{ Total $n$ of sources: 20} & $\mathrm{RCT} n=12$ & $n=33$ & Yes: $n=16$ & Yes: $n=12$ & PT/OT journals: $n=2$ \\
\hline & $\mathrm{SR} n=4$ & & No: $n=2$ & No: $n=6$ & OHD: $n=16$ \\
\hline & MA $n=2$ & & N/A: $n=1$ & N/A: $n=2$ & Other: $n=2$ \\
\hline & Reviews $n=4$ & & TBA: $n=1$ & & \\
\hline
\end{tabular}

SR, systematic review; RCT, randomized controlled trial; MA, meta-analysis.

\section{EBP model step 4: treatment planning and recommendations}

Figure 4 illustrates the eight categories of treatment recommendations and the rating (must be done, can be done, or does not need to be done) reflecting the relative importance of each recommendation derived from the consensus building focus group. Participants reported that although all the listed interventions may be appropriate when deciding on a treatment plan for a patient with a history of falls, seven of the eight final categories of interventions targeted the specific needs of the patient depicted in the vignette. Overall, when asked to list which EBP components (clinical experience, patient choice, research evidence) were used to support these decisions, participants agreed that two of the five necessary recommendations (comprehensive discharge plan and assessment of footwear) were based on clinical experience (1/3 EBP components) and three (multifactorial fall prevention program, CLSC interventions at home and in-patient rehabilitation and education) were based on a combination of the evidence from the literature participants had read in combination with their clinical experience (2/3 EBP components).

\section{EBP model step 5: evaluation of intervention outcomes}

Eight categories of possible causes for the recurrence of falls emerged from the analysis. There was no mention of compliance with fall prevention recommendations or effectiveness of the fall prevention program as potential causes. During the second focus group, participants reported that recurrence of falls is a complex phenomenon caused by a combination of patient and contextual factors. The patient-specific causes 


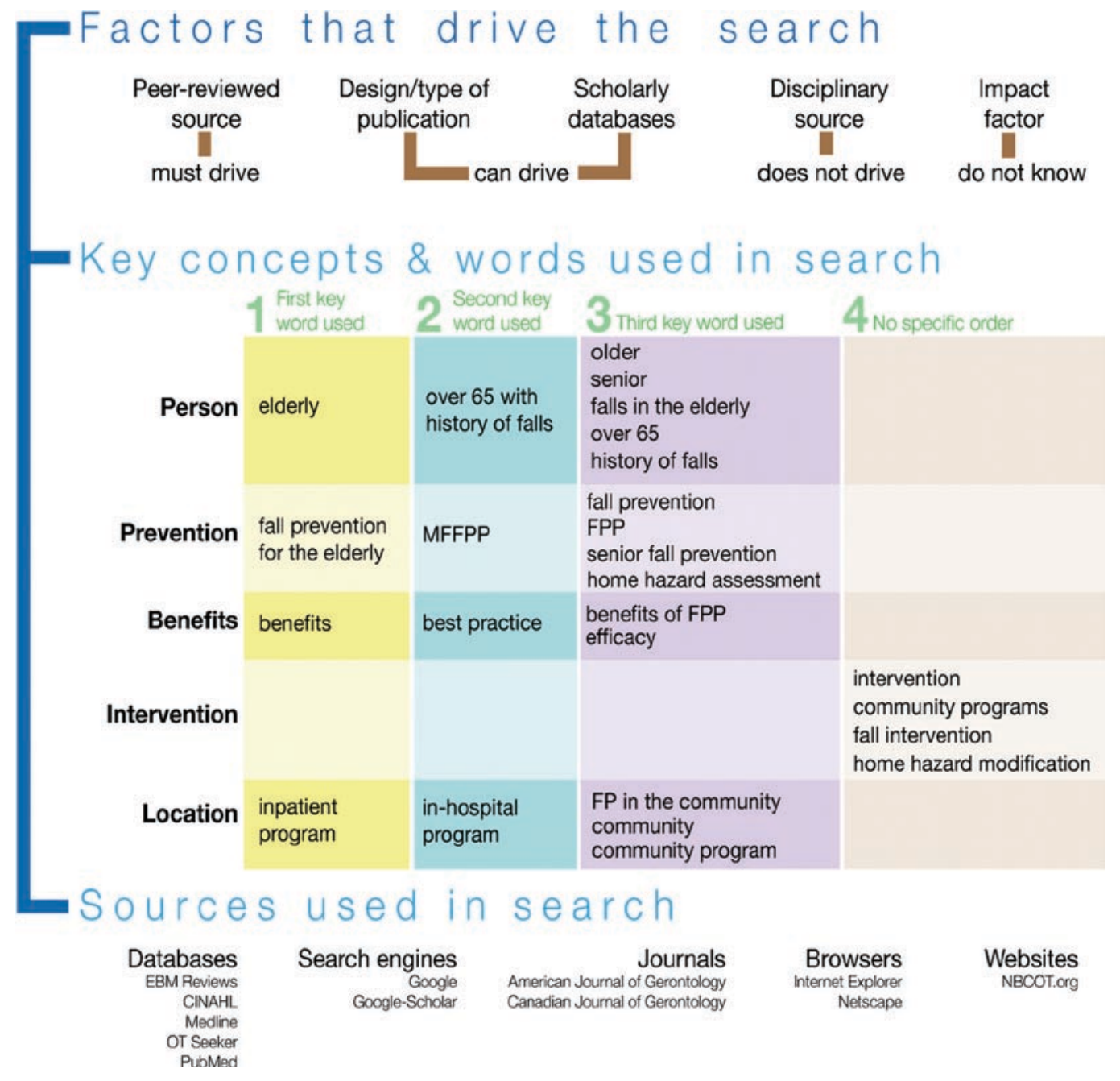

Figure 2. EBP reference model step 2: searching for literature.

(all expect 'environmental/extrinsic factor' in Figure 5) are more likely to contribute to the recurrence, than failure of one or more components of the multifactorial fall prevention program. Participants unanimously reported that their extensive clinical experience facilitated the identification of a wide repertoire of causes that are considered relative to each patient. Participants reported that neither the literature nor the patient's input guided this process.

Figure 5 shows the eight categories of new actions (following the recurrence of falls) and the order in which they would be offered. Participants identified one necessary intervention: a family meeting to discuss the circumstances of the fall and coordinate additional resources as needed. The remaining seven categories derived from clinician consensus, represent possible actions in the event that the main intervention fails. None of the participants mentioned the need for or the importance of re-examining any of the previous EBP steps nor was there any mention of reassessing personal proficiency in searching, appraising and implementing the research evidence which are normally done in the last EBP step. The revised plan of action was also exclusively derived from clinical experience (one of the three components of EBP).

\section{Reference model representing expert clinicians' evidence based practice behaviors}

Figures 1-5 represent the EBP reference model created from the decisions of experienced clinicians in the area of falls prevention in the elderly. Each step in the reference model includes the categories and concepts that delineate the actions and decisions that are made for a patient with a history of falls. The model also includes rankings that illustrate the importance attributed to certain decisions as well as the actions that are supported by clinical experience, scientific evidence and patient choice.

\section{Discussion}

The objective of this study was to develop an OT reference model in the area of fall prevention in the elderly and identify the extent to which participants adhered to the principles of EBP as part of their clinical decision-making for a written simulated case. There was variability and breadth in participants' responses in steps 2, 4 and 5 of the EBP process. Individual searches for literature (Step 2) did not yield any common articles. Interestingly, more than half of the articles reported 


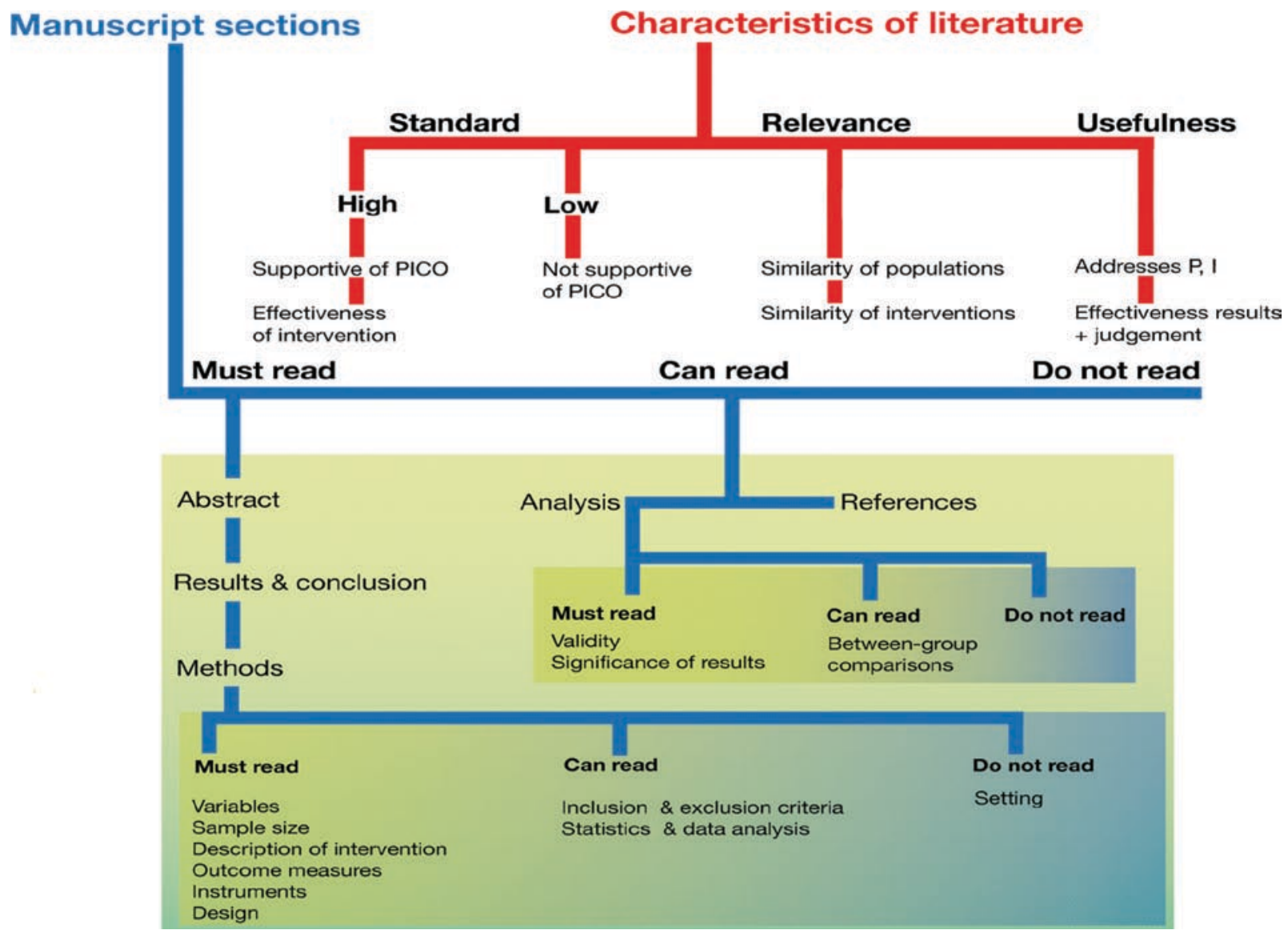

Figure 3. EBP reference model step 3: appraisal of literature.

results of randomized controlled trials, systematic reviews and meta-analyses. Considering the volume of published research on this topic and the position of these research designs on the evidence hierarchy [10] this finding is reassuring. Although the present study did not examine participants' knowledge of research, their selection of published articles with rigorous research methodologies suggests some basic knowledge of research methods. The number of categories and key words for searching the literature suggests that clinicians rely on a broad list of synonyms which they use interchangeably or in sequence depending on the success of their search. Thus, while overall, they may end up using the same set of keywords and databases, it may be that because of the sequence of the entry in their searches, their yield is not identical. It is also possible that when they originally conducted the literature searches (on their own time and individually) they may have used different terms. Only through the process of group discussion and consensus with the other participants, they arrived at a particular set of key words included in the reference model.

The extensive lists of recommendations in Step 4 and causes of recurrence and new action plan in Step 5 suggest two things. First, that optimal management of a complex clinical scenario hinges on a combination of treatment interventions. Second, that clinicians' experience with numerous patients through the years has contributed to a rich and well organized body of knowledge from which participants are drawing in order to effectively identify causes of falls and select appropriate interventions [40-42]. Consistent with expertise research findings in other domains [41,42], extended experience in falls prevention has likely resulted in participants having developed a set of patterns and cues regarding patients with a history of fall. Clinicians are able to successfully recognize similar patterns and draw from cues presented in the current clinical situation in order to effectively solve a problem (find the possible causes of recurrence and consider subsequent interventions). In the final step of the EBP process where participants listed their new plan of action, neither a review of the EBP process nor an assessment of their individual proficiency with the process were considered to be possible new actions. Although the EBP process is supposed to culminate in a review of the outcome of the intervention for which scientific evidence is sought and that individual reflection and reassessment are believed to be crucial in improving one's aptitude in EBP, these actions may not be congruent with clinicians' demanding caseloads or their knowledge of the EBP process.

There was limited variability in responses to steps 1 and 3. Without additional data on clinicians' knowledge of PICO and EBP prior to this study, it is not possible to make any conclusions on why participants' PICO questions (step 1) were so similar. The variability in step 3 (appraising the literature), even though only two participants provided responses to this section, suggests limited familiarity and skill in critical 


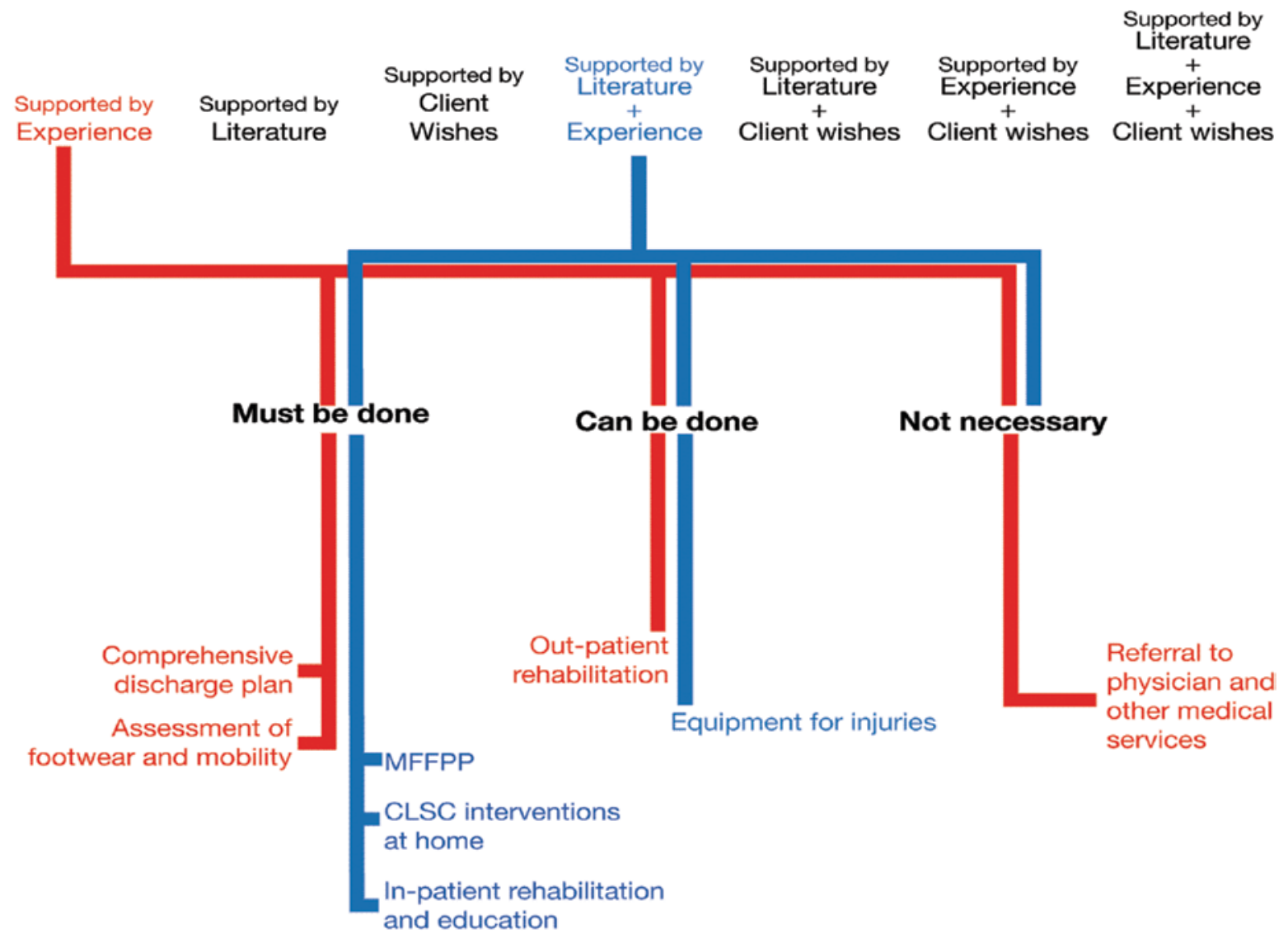

Figure 4. EBP reference model step 4: decision-making/client recommendations.

appraisal which is consistent with the findings from the literature presented earlier in this paper [18,21-25]. Variability in responses may also be due to individual differences in clinical expertise and the extent of participants' experience in the area of falls prevention. While this study did not examine any of the individual attributes of expertise mentioned earlier, evidence from the expertise literature in professional domains indicates that such differences do exist [53,7-90]. Looking at participants' experiences, it is evident that experiences vary both quantitatively and qualitatively (i.e., the type of involvement). With respect to the former, the number of years of clinical practice ranges from 9 to 20 as does the frequency with which participants engage in fall prevention activities. As to the latter, it can be noted that some participants took part in specialized activities within prevention of falls such as developing new programs or creating written documents for patient education whereas others participated in only basic patient education. These qualitatively different experiences may be linked to the mandates of the various clinical sites which offer OT services according to the patients' stage in the recovery process (rehabilitation vs. community setting). Rehabilitation centers offer services targeting remedial treatments for fractures, education on preventing falls and preparation for discharge, whereas community settings normally follow patients in their home for maintenance with minimal if any form of remediation. Where there is a mandate to offer intensive treatment for prevention of falls, clinicians will necessarily be forced to use targeted interventions that can eventually translate into greater exposure and experience in this domain.

The data do not allow for drawing any resolute conclusions regarding the role of deliberate practice in explaining individual differences in EBP behaviours. In most areas of OT, clinicians do not select and deliberately introduce interventions in order to improve their proficiency in those interventions. Rather, the 'practice' of falls prevention interventions is a function of the therapists' caseload, their knowledge of the clinical area, their ease with different interventions and the availability of resources (equipment, physical space). Deliberate practice may be a mediating mechanism for the development of expertise in this area but only under certain conditions. The precise conditions (circumstances and facilitators) under which a clinician is compelled to engage in purposeful practice in order to attain superior levels of competence in this area require further study. Deliberate practice may have a role in the development of expertise in OT professional contexts such as falls prevention, but this is probably unlike deliberate practice in domains such as music or sports where an individual practices purposefully for a number of hours daily, with feedback and supervision in order to improve performance [37-39]. Opportunities for an OT to engage in this kind of deliberate practice are seriously limited if the clinical context does not afford regular and appropriate patient cases.

The study findings have shown that being an expert OT clinician is not synonymous with being an expert evidencebased practitioner. The expert clinicians did not integrate all 


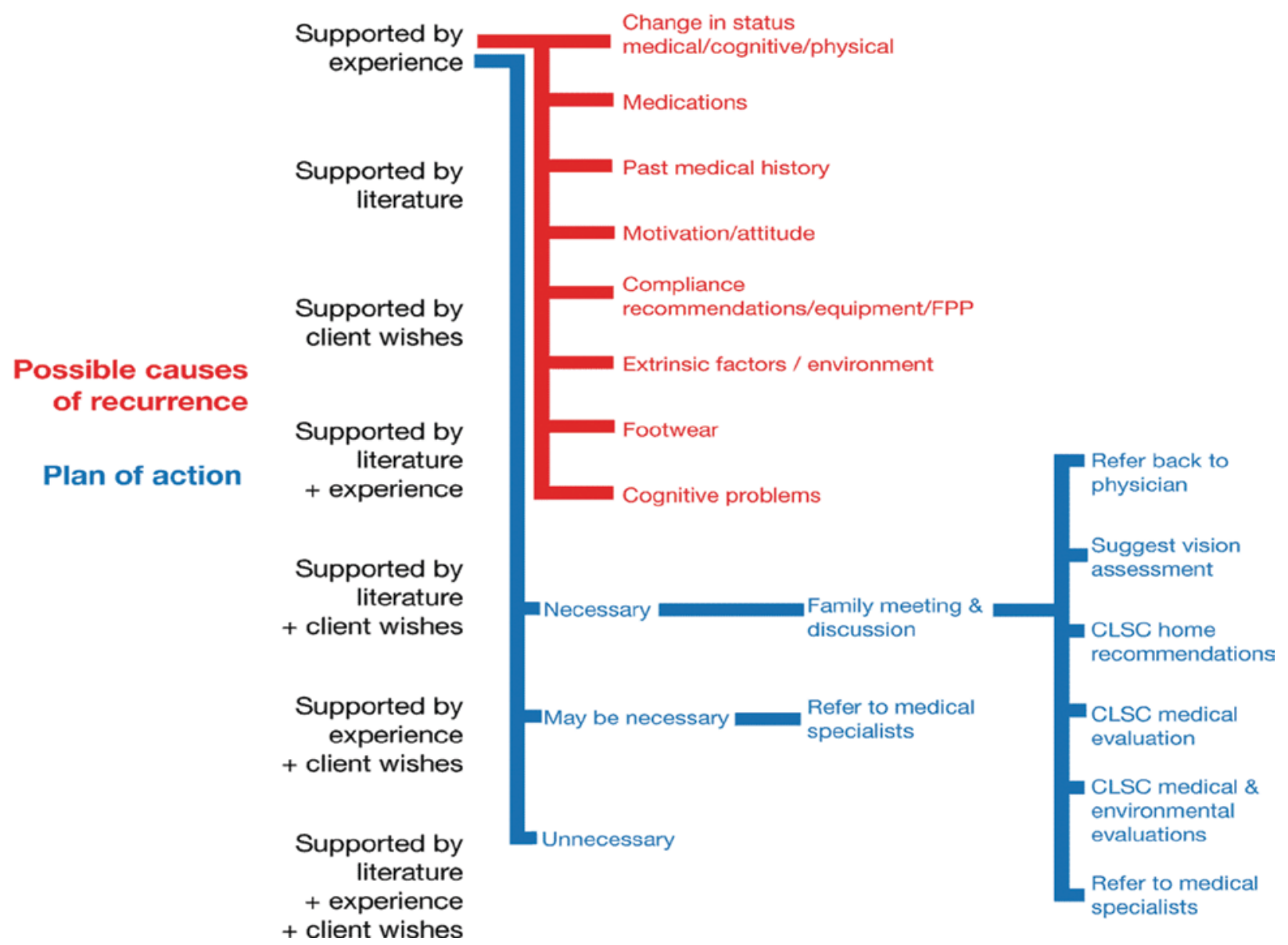

Figure 5. EBP reference model step 5: evaluation of outcome.

EBP components (scientific evidence, clinical experience and patient choice) in their clinical decisions for the patient depicted in the vignette. One third of their recommendations were informed by research evidence and the majority of decisions were based primarily on past experiences with patients with similar problems (Figure 5). This finding is consistent with the notion of the "evidential knowledge base" which has been reported as necessary in clinical practice [91]. Scientific evidence alone, without knowledge and experience in a domain, does not speak for itself. Thus, clinicians must rely on their clinical experiences to judge if and how they will use the scientific evidence. Although additional data regarding clinicians' motives for relying primarily on clinical experience would be needed to explain this finding, there are a number of possible explanations. First, all seven participants were trained during a period where EBP was not part of OT professional education. As it has been suggested, novice clinicians are more likely to utilize evidence in practice than more seasoned practitioners most probably because of the recency of exposure to EBP in their university training $[92,93]$. Second, time since graduation seems to influence the extent to which a clinician stays abreast of and uses current best evidence. The average number of years since graduation in our sample was 18 years. EBP was not a foreign concept for participants; however, they were not familiar with the details of the EBP approach and/or the five-step process. Third, participants may have experienced a number of the EBP barriers earlier in their practice, which may have deterred them from adopting this approach. Although potential inhibiting reasons were not explored in this study, several participants in informal discussions following both focus groups, reported that in the "real world", issues such as busy case loads and increasingly demanding patients with complex co-morbidities were discouraging them from using an EBP approach. These barriers have also been identified by other researchers $[4,6,19,18]$. Fourth, clinicians may have been either unaware that there is current evidence in falls prevention or they may not have been recently involved in any continuing education initiatives on best practices in this domain. Interestingly, a recent systematic review of strategies for rehabilitation professionals (occupational therapists and physical therapists) to move evidence-based knowledge into practice [94] showed that multi-component knowledge translation interventions were effective for enhancing knowledge and practice behaviours of physical therapists but were unsuccessful in producing changes in OTs' clinical practices. Though this review included very few studies specifically of OTs, findings suggest that even if our sample of clinicians had participated in such knowledge translation strategies, we most likely would not have observed differences in EBP behaviours in the present study. Fifth, relying primarily on clinical experience is consistent with other studies on best practice behaviours in OTs $[17,18,21]$. Indeed, 
perceptions that clinical experience is paramount even in the presence of research evidence may influence if and under what circumstances scientific findings are considered and ultimately incorporated in practice. Others [95] have suggested that an underlying factor, or practice style trait, may influence if and how a clinician responds to new information. Practice style may be influenced by what is considered as credible sources of evidence, the value attributed to evidence vs. experience, the importance attributed to practical issues such as managing workload vs. patient satisfaction and the readiness to diverge from group norms (issues of non-conformity) [95]. A study on the prevalence of practice style traits of physical and occupational therapists working in stroke rehabilitation showed that most therapists were 'pragmatists' according to the practice style questionnaire $[95,96]$. Pragmatists, who focus on the day to day demands of clinical practice and who are primarily concerned about efficiency, may be willing to "diverge from local norms" [95] (p. 939) but only if this is not disruptive to their practice. In contrast, very few clinicians in that study were 'seekers' whose clinical practice was driven by scientific evidence. It is therefore possible that in the present study, participants' reporting that experience was the main driving force behind most clinical decisions is in part due to an underlying practice style trait.

Findings from the present study suggest that arriving at one common end-point regarding EBP in falls prevention is not straightforward. Complex patient scenarios appear to require a broad range of actions within the EBP process particularly in steps 4 and 5 . Hence, it may be a challenge to integrate all components of the EBP process when trying to make a clinical decision about a fall prevention intervention. Given the extensive list of responses in those two steps and clinicians' reports that there is no "one size fits all" approach to managing patients with falls, expert practice in prevention of falls may be a function of the individual and unique needs of each patient. If accurate, this explanation would be consistent with the patient-centered philosophy of OT. This explanation may even appease critics who argue that patient-centered OT practice is inconsistent with EBP and that unless the patient is included in every step of the process, clinicians risk sacrificing the profession's espoused philosophy of patient-centeredness. Results from the study reported herein, however, do not present any evidence that the proposed interventions involved patient input. This was an unexpected and surprising finding.

Expert practice in prevention of falls appears to manifest itself in a broad repertoire of possible explanations for the aetiology of falls and in a range of treatment interventions that are largely based on extensive clinical experience in the domain. Expert OTs can proceed through the EBP process with cueing. In the absence of a structure that scaffolds clinicians through this process, the same experts rely primarily on their experience and their extensive knowledge of their patients to make a clinical decision. Even when the EBP process is clearly outlined, clinicians fall short in clearly articulating a clinical question and searching for and appraising the literature. This is most likely due to their limited knowledge and skill in steps 1 through 3 which most OT academic programs have just recently begun teaching explicitly as part of the EBP curriculum. Decisions in steps 4 and 5 of the process include fewer and more precise concepts which may reflect clinicians' highly organized and structured experiential knowledge.

A final discussion point is if and how the EBP approach in the context of falls prevention, adds value to clinical practice. For the most part, the OTs in the study based their clinical decisions on previous clinical experiences with the majority of fall prevention recommendations still in use primarily because of their supposed success over the years. While this may not automatically result in ineffective or hazardous decisions, the practice of selecting treatments mainly because they have always worked may be leading OTs down a slippery slope. Clinical experience alone does not replace EBP. Clinical decisions must be based on a weighted use of expert judgment, patient-centered practice, clinical experience and scientific evidence. These necessary components of the evidence-based OT process work together, albeit at varying degrees and for different situations, to address the unique occupational needs of individuals living with disabilities. The question of whether under specific conditions clinical experience in falls prevention is sufficient and whether it can, to some extent, compensate for limited research knowledge and uptake, requires further study.

The reference model of expert OT practice in falls prevention for an elderly population with a history of falls generated in this study is a useful reference model for what expert clinicians likely do, what aspects of the process are in line with EBP and what aspects of EBP are missing. The model identifies which actions are influenced by experience, research evidence and patient input.

\section{Implications for practice}

The research reported in this paper is the first to attempt to capture the EBP behaviours of expert clinicians in one area of OT practice and create a reference model that illustrates the expert behaviours that are consistent with all three components of EBP and those that are primarily driven by clinical experience. Study results have the potential to contribute to EBP practice and education. The findings broaden the existing knowledge base regarding experts' practice behaviours in the area of falls prevention in every day practice terms. Results support existing evidence that most clinicians rely primarily on their clinical experience to guide clinical decision-making. Clinicians can make deliberate efforts to think about and incorporate EBP principles when scaffolded through the EBP process despite limited knowledge of concepts such as PICO and limited skill in searching and appraising the literature. Also from a practice point of view, a possible contribution of this study is the potential for the resulting model to be used in OT as a practice framework. Clinicians working in prevention of falls in geriatric rehabilitation can use the model to guide them through the steps of the decision-making process regarding interventions for falls prevention. With further validation, the model generated in this study can also be used as a framework for teaching and assessment in OT education. In order to help students acquire expert practice competencies in falls prevention, educators can use the model to: 1) demonstrate the expert actions 
taken to arrive at a clinical decision regarding falls prevention including aspects of the decision-making process that are and are not congruent with EBP, 2) develop teaching activities that help students move along the decision-making process and 3) assess students' competence in decision-making by comparing their responses to the responses of expert OT clinicians depicted in the model. Finally, the methodology from this study can be used for developing models of expert practice in other domains of OT where there is available scientific evidence such as stroke and cerebral palsy.

\section{Study limitations}

The first limitation in the study is related to the data collection process. Clinicians completed the task on their own time over a 12-week period. Even though they were given direction as to what resources they could use, they may have used other resources or their responses to the questions may have been influenced by interruptions caused by clinical duties or their help seeking from others. A second limitation is that this research was conducted in one area of OT practice. Although there is ample scientific evidence to draw from when making a clinical decision about fall prevention programs, the results are specific to this area of OT practice and may therefore have limited generalizability. Lastly, the inclusion criteria (being identified as an expert clinician by supervisors, 10 years of clinical OT experience or more, extensive experience in geriatrics and regular participation in prevention of falls programs) are only robust criteria insofar as the insights we have from the current literature on expertise. Only future research findings will be able to shed light on the conclusiveness of the inclusion criteria for the sample included in this study.

\section{Directions for future research}

This study is the first to systematically identify features of expert OT clinical decision-making in one area of OT practice. As such, it has uncovered important insights into expert practice in this area and pointed to interesting directions for further research. Given the apparent shortcomings in the application of EBP, it would be worthwhile to generate a model created by a group comprised of clinicians, researchers and academics with recognized expertise in EBP. The knowledge and behaviors gleaned from these experts could be used to create more comprehensive representations of expert EBP in specific domains of OT practice. Given that there are researchers who study EBP and that most academics in OT programs are involved in teaching EBP, identifying these experts should not be a challenge. Identifying clinician experts in EBP however, may prove to be a far greater challenge in light of recent studies which have shown that most OT clinicians are not readily using research evidence to support their practice. With ongoing efforts to move knowledge into practice, as evidenced by the sharp rise in knowledge translation studies, we may witness a move towards increased use of best practices. If knowledge translation strategies prove to be successful in changing clinicians' behaviours, there may be a larger pool of experienced clinicians with recognized skills and expertise in EBP to draw from when attempting to create expert models of EBP. Future research on the development of expert EBP models will likely need to go hand in hand with knowledge translation studies.

Another avenue for research on the development of expert models includes replicating the methodology used in this study in other areas of OT practice where there is existing scientific evidence to validate the approach. Emerging scientific evidence for rehabilitation interventions in areas such as stroke and cerebral palsy provides fertile ground for additional testing of this methodology.

This study captured the decisions of experienced OT clinicians in one area of practice. Although not all of the behaviours were consistent with all of the EBP principles, the reference model does illustrate expert OT decision-making in falls prevention. It would be worthwhile to examine the differences in clinical decision-making for falls prevention, amongst clinical experts with no recognized expertise in EBP and expert evidence-based OT practitioners. This comparison could yield important data regarding the differences in the nature of the patient-centered clinical decisions and the specific conditions under which scientific evidence is integrated in practice.

Another possible avenue for research that extends from this study would involve examining clinicians' EBP behaviours in real time and authentic contexts. There are two major advantages in using real patients in investigations of EBP. The first is that OT clinicians will have the opportunity to assess the impact of their evidence-based interventions, assess their own proficiency with the EBP approach and make plans for improvement. Ultimately, these actions can help clinicians to further hone both their clinical skills and their EBP skills. The second advantage, relates to researchers observing the actual outcomes that result from clinical decisions supported by research findings. Results from studies conducted in authentic contexts could begin to answer a question which has been raised by sceptics of the EBP movement: Does EBP lead to superior care and improved clinical outcomes? To gain greater insights into the reasons for clinicians' EBP decisions and examine what underlying cognitive processes may be supporting the decisions made in EBP, future studies using qualitative methodologies and cognitive task analyses could be used. This kind of research could be conducted with clinicians in different practice areas and with varying levels of experience. Regardless of which of the above mentioned research avenues are pursued, future studies of expert models in OT will have to take into account developments in expertise research that are grounded in cognitive psychology as well as current developments in knowledge translation.

Declaration of interest: The research reported in this paper was funded by a doctoral fellowship from the Fonds Quebecois de Recherche sur la Société et la Culture, Quebec Provincial Government and the Centre de recherche interdisciplinaire en réadaptation du Montréal métropolitain. 


\section{References}

1. Bennett S, Bennett JW. The process of evidence-based practice in occupational therapy: Informing clinical decisions. Aust Occup Ther J 2000;47:171-180.

2. Evidence-Based Medicine Working Group. Evidence-based medicine: A new approach to teaching the practice of medicine. J Am Med Assoc 1992;268:2420-2425.

3. Lloyd-Smith W. Evidence-based practice and Occupational Therapy. Br J Occup Ther 1997;60:474-478.

4. Cameron KA, Ballantyne S, Kulbitsky A, Margolis-Gal M, Daugherty T, Ludwig F. Utilization of evidence-based practice by registered occupational therapists. Occup Ther Int 2005;12:123-136.

5. Salls J, Dolhi C, Silverman L, Hansen M. The Use of EvidenceBased Practice by Occupational Therapists. Occup Ther Health Care 2009;23:134-145.

6. Korner-Bitensky N, Wood-Dauphinee S, Teasell R, Desroisers J, Malouin F, Thomas A, Harrison M, Hanley J, Kaizer F, Kehayia E, Menon-Nair A, Rochette A, Dumoulin C. Best versus actual practices in stroke rehabilitation: Results of the Canadian National Survey. Stroke 2006;37:631.

7. Philibert DB, Snyder P, Judd D, Windsor MM. Practitioners' reading patterns, attitudes, and use of research reported in occupational therapy journals. Am J Occup Ther 2003;57:450-458.

8. Alexander PA. The development of expertise: The journey form acclimation to proficiency. Educ Res 2003;32:10-14.

9. Lajoie SP. Transitions and trajectories for studies of expertise. Educ Res 2003;32:21-25.

10. Sackett DL, Straus SE, Richardson WS, Rosenberg WM, Haynes RB. Evidence-based medicine. How to practice and teach EBM. 2nd Edn. Edinburgh: Churchill, Livingston 2000.

11. Corcoran M. A busy practitioner's approach to evidence-based practice. Am J Occup Ther 2006;60:127-128.

12. Straus SE, Ball C, Balcombe N, Sheldon J, McAlister FA. Teaching evidence-based medicine skills can change practice in a community hospital. J Gen Intern Med 2005;20:340-343.

13. Tickle-Degnen L. Gathering current research evidence to enhance clinical reasoning. Am J Occup Ther 2000;54:102-105.

14. Duncan PW, Zorowitz R, Bates B, Choi JY, Glasberg JJ, Graham GD, Katz RC, et al. Management of Adult Stroke Rehabilitation Care: a clinical practice guideline. Stroke 2005;36:e100-e143.

15. Lindsay P, Bayley M, Hellings C, Hill M, Woodbury E, Phillips S. Canadian best practice recommendations for stroke care (updated 2008). J Can Med Assoc 2008;179:S1.

16. Menon-Nair A, Korner-Bitensky N, Ogourtsova T. Occupational therapists' identification, assessment, and treatment of unilateral spatial neglect during stroke rehabilitation in Canada. Stroke 2007;38: 2556-2562.

17. Humphris D, Littlejohns P, Victor C, O'Halloran P, Peacok J. Implementing evidence-based practice factors that influence the use of research evidence by occupational therapists. Br J Occup Ther 2000;63:516-522.

18. Bennett S, Tooth L, McKenna K, Rodger S, Strong J, Ziviani J, Mickan S, Gibson L. Perceptions of evidence-based practice: A survey of Australian occupational therapists. Aust Occup Ther J 2003;50:13.

19. Dysart AM, Tomlin GS. Factors related to evidence-based practice among U.S. occupational therapy clinicians. Am J Occup Ther 2002;56:275-284.

20. Craik J, Rappolt S. Theory of research utilization enhancement: a model for occupational therapy. Can J Occup Ther 2003;70:266-275.

21. Dubouloz CJ, Egan M, Vallerand J, von Zweck C. Occupational therapists' perceptions of evidence-based practice. Am J Occup Ther 1999;53:445-453.

22. Salbach NM, Jaglal SB, Korner-Bitensky N, Rappolt S, Davis D. Practitioner and organizational barriers to evidence-based practice of physical therapists for people with stroke. Phys Ther 2007;87:1284-1303.

23. Teasell RW., Foley NC, Salter K, Bhogal SK, Jutai J, Speechley MR. Evidence-Based Review of Stroke Rehabilitation. 11th Edn. Canadian Stroke Network 2008.

24. Tse S, Lloyd C, Penman M, King R, Bassett H. Evidence-based practice and rehabilitation: occupational therapy in Australia and New Zealand experiences. Int J Rehabil Res 2004;27:269-274.

25. Welch A, Dawson P. Closing the gap: collaborative learning as a strategy to embed evidence within occupational therapy practice. J Eval Clin Pract 2006;12:227-238.
26. Rochette A, Korner-Bitensky N, Thomas A. Changing clinicians' habits: is this the hidden challenge to increasing best practices? Disabil Rehabil 2009;31:1790-1794.

27. Davidoff F. In the teeth of the evidence: the curious case of evidencebased medicine. Mt Sinai J Med 1999;66:75-83.

28. Haynes RB. What kind of evidence is it that Evidence-Based Medicine advocates want health care providers and consumers to pay attention to? BMC Health Serv Res 2002;2:3.

29. Rappolt S. The role of professional expertise in evidence-based occupational therapy. Am J Occup Ther 2003;57:589-593.

30. Rolfe G. Insufficient evidence: the problems of evidence-based nursing. Nurse Educ Today 1999;19:433-442.

31. Sackett DL, Rosenberg WM, Gray JA, Haynes RB, Richardson WS. Evidence based medicine: what it is and what it isn’t. BMJ 1996;312: 71-72.

32. Devereaux PJ, Guyatt GH. Clinical expertise in the era of evidencebased medicine and patient choice. ACP J Club 2002;136:A11-A14.

33. Sackett DL, Rosenberg WM, Richardson WS, Haynes RB. Evidencebased medicine. How to practice and teach EBM. 2nd Edn. Edinburgh: Churchill, Livingston 1997.

34. Chi MTH, Glaser R, Farr M. The nature of expertise. Hillsdale, NJ: Lawrence Erlbaum Associates; 1988.

35. Glaser R, Lesgold A, Lajoie SP. Toward a cognitive theory for the measurement of achievement. In: Ronning RR, Glover J, Conoley, JC, Witts JC, (eds). The influence of cognitive psychology on testing. Hillsdale, NJ: Lawrence Erlbaum Associates; 1987. pp. 41-85.

36. Ericsson KA, Krampe RT, Tesch-Römer C. The role of deliberate practice in the acquisition of expert performance. Psych Rev 1993;100: 363-406.

37. Ericsson KA. The scientific study of expert levels of performance: General implications for optimal learning and creativity. High Abil Stud 1998;9:75

38. Ericsson KA. The path to expert performance: Insights from the masters on how to improve performance by deliberate practice. In: Thomas P, (eds). Optimizing performance in golf. Brisbane. Australia: Australian Academic Press; 2001. pp. 1-57.

39. Ericsson KA. Deliberate practice and the acquisition and maintenance of expert performance in medicine and related domains. Acad Med 2004;10:S1-S12.

40. Bransford JD, Brown A, Cocking R. How People Learn: Brain, Mind, Experience, and School. Washington, DC: National Academy Press. 2000.

41. Ericsson KA, Smith J. Toward a general theory of expertise: Prospects and limits. Cambridge, UK: Cambridge University Press.1991.

42. Lesgold A, Rubinson H, Feltovich P, Glaser R, Klopfer D, Wang Y. Expertise in a complex skill: Diagnosing X-ray pictures. In: Chi MTH, Glaser R, Farr MJ, (eds). The nature of expertise Hillsdale. NJ: Erlbaum; 1988. pp. 311-342.

43. Ericsson KA. The influence of experience and deliberate practice in the development of superior expertise and performance. In: Ericsson KA, Charness, N, Feltovitch PJ, Hoffman RR, (eds). The Cambridge Handbook of Expertise and Expert Performance. Cambridge: Cambridge University Press; 2006; pp. 685-705.

44. Gilhooly KJ, McGeorge P, Hunter J, Rawles JM, Kirby IK, Green C, Wynn V. Biomedical knowledge in diagnostic thinking: The case of electrocardiogram (ECG) interpretation. Eur J Cognit Psychol 1997;9: 199-223.

45. Anderson JR. Acquisition of cognitive skills. Psychol Rev 1982;89: 369-406.

46. Chi MTH, Feltovich PJ, Glaser R. Categorization and representation of physics problems by experts and novices. Cognit Sci 1981;5: 121-152.

47. Ericsson KA. The acquisition of expert performance: An introduction to some of the issues. In: Ericsson KA, (eds). The Road to Excellence: The Acquisition of Expert Performance in the Arts and Sciences, Sports, and Games. Mahwah, NJ: Erlbaum; 1996. pp. 1-50.

48. Glaser R, Chi MTH. Overview. In: Chi MTH, Glaser R, Farr M, (eds). The Nature of Expertise. Hillsdale, NJ: Erlbaum; 1988. pp. 15-28.

49. Klein GA. A recognition-primed decision (RPD) model of rapid decision making. In: Klein GA, Orasanu J, Calderwood R, Zsambok CE, (eds). Decision making in action: models and methods. Norwood, NJ: Ablex 1993. pp. 138-147.

50. Chi, MTH, Glaser R, Rees E. Expertise in problem solving. In: Sternberg R, (eds). Advances in the Psychology of Human Intelligence. Hillsdale, NJ: Erlbaum; 1982. pp. 7-75. 
51. Chi, MTH. Knowledge structures and memory development. Children's thinking: What develops? In Siegler, RS, (eds). Children's thinking: What develops? Hillsdale, NJ: Lawrence Erlbaum Associates, Inc; 1978. pp. 73-96.

52. Feltovich PJ, Barrows HS. Issues of generality in medical problem solving. In H. G. Schmidt HG \& DeVolder ML, (eds). Tutorials in problem-based learning: New directions in training for the health professions. Assen, The Netherlands: Van Gorcum, 1984.

53. Patel VL, Groen G. Knowledge based solutions strategies in medical reasoning. Cognit Sci 1986;10:91-116.

54. Patel VL, Groen G. The general and specific nature of medical expertise: A critical look. In Ericsson KA, Smith J, (eds). Towards a General Theory of Expertise. Cambridge, England: Cambridge University Press, 1991. pp. 93-125.

55. Patel VL, Kaufman DR. Clinical reasoning and biomedical knowledge: implications for teaching. In Higgs J, Jones M, (eds). Clinical reasoning in the health professions. Oxford, England: ButterworthHeinemann Ltd, 1995. pp. 117-128.

56. Schmidt HG, Boshuizen HPA. On acquiring expertise in medicine. Educ Psych Rev 1993;5:205-221.

57. Schmidt HG, Norman GR, Boshuizen HP. A cognitive perspective on medical expertise: theory and implication. Acad Med 1990;65: 611-621.

58. Schmidt HG, Boshuizen HPA, Norman GR. Reflections on the nature of expertise in medicine. In E. Keravnou, (eds). Deep models for medical knowledge engineering. Amsterdam: Elsevier, 1992. pp. 231-248.

59. Benner P. From novice to expert. Am J Nurs 1982;82:402-407.

60. Benner P. From novice to expert. Menlo Park. CA: Addison-Wesley. 1984.

61. Daley JB. Novice to expert: An exploration of how professionals learn. Ad Educ Quart, 1999;49:133-147.

62. Dreyfus H, Dreyfus S. A five-stage model of the mental activities involved in direct skill acquisition. Unpublished report supported by the Air Force office of Scientific Research, University of California at Berkeley, 1980

63. Hamers HPJ, Van Den Hout AM, Halfens JGR, Abu-Saad HH, Heijltjes EGA. Differences in pain assessment and decisions regarding the administration of analgesics between novices, intermediates and experts in pediatric nursing. Intern J of Nurs Stud 1997:34:325-334.

64. Welsh I, Lyons CM. Evidence-based care and the case for intuition and tacit knowledge in clinical assessment and decision making in mental health nursing practice: an empirical contribution to the debate. J Psychiatr Ment Health Nurs 2001;8:299-305.

65. O'Byrne RK, Goodyear KR. Patient assessment by novice and expert psychologist: A comparison of strategies. Educat Psychol Rev 1997:9:267-278.

66. Norman G, Eva K, Brooks L, Hamstra S. Expertise in medicine and surgery. In K. A. Ericsson KA, Charness N, Feltovich PJ, Hoffman RR, (eds). The Cambridge handbook of expertise and expert performance. Cambridge, UK: Cambridge Univ. Press. 2006. 339-354.

67. Choudhry NK, Fletcher RH, Soumerai SB. Systematic review: the relationship between clinical experience and quality of health care. Ann Intern Med 2005;142:260-273.

68. Ericsson KA, Kintsch W. Long-term working memory. Psychol Rev 1995;102:211-245.

69. Ericsson KA, Lehmann AC. Expert and exceptional performance: evidence of maximal adaptation to task constraints. Annu Rev Psychol 1996;47:273-305.

70. Vicente KJ, Wang JH. An ecological theory of expertise effects in memory recall. Psychol Rev 1998;105:33-57.

71. Hoffman RR. The psychology of expertise: Cognitive research and empirical AI. Mahwah, NJ: Erlbaum. 1992.

72. Doane SM, Pellegrino JW, Klatzky RL. Expertise in a computer operating system: Conceptualization and performance. Hum Comp Inter 1990;5:267.

73. Reif F, Allen J. Cognition for interpreting scientific concepts: A study of acceleration. Eth \& Behav 1992;9:1.

74. Dawes RM. House of cards: Psychology and psychotherapy built on myth. New York: Free Press. 1994.
75. Sonnentag S. Expertise in professional software design: a process study. J Appl Psychol 1998;83:703-715.

76. Camerer CF, Johnson EJ. The process-performance paradox in expert judgment: How can the experts know so much and predict so badly? In K.A. Ericsson KA, Smith J, (eds). Toward a general theory of expertise: Prospects and limits. Cambridge, England: Cambridge University Press.1991. pp. 195-217.

77. Chi MTH. Two approaches to the study of experts' characteristics. In Charness N, Feltovich P, Hoffman RR, (eds). Cambridge handbook of expertise and expert performance. Cambridge: Cambridge University Press. 2006. pp. 21-27.

78. Patel VL, Yoskowitz NA, Arocha JF, Shortliffe EH. Cognitive and learning sciences in biomedical and health instructional design: A review with lessons for biomedical informatics education. J Biomed Inform 2009;42:176-197.

79. Jones TV, Gerrity MS, Earp J. Written case simulations: do they predict physicians' behavior? J Clin Epidemiol 1990;43:805-815.

80. Rutten GM, Harting J, Rutten ST, Bekkering GE, Kremers SP. Measuring physiotherapists' guideline adherence by means of clinical vignettes: a validation study. J Eval Clin Pract 2006;12:491-500.

81. Swanson DB, Barrows HS, Friedman CP, Levine HG, Norman GR. Issues in assessment of clinical competence. Prof Educ Res Notes 1982;4:2.

82. Moskowitz JA, Kuiers, JB, Kassirer, PJ. Dealing with uncertainty, risks, and tradeoffs in clinical decisions: A cognitive science approach. Ann of Inter Med 1988;108:435-449.

83. Morgan DL. Focus groups. Annual Rev Sociol 1996;22:129.

84. Creswell JW, Miller DL. Determining validity in qualitative inquiry. Theor into Pract 2000;39:124.

85. Creswell JW. Qualitative inquiry \& research design: Choosing among five approaches. Thousand Oaks, CA: Sage Publications, Inc. 2007.

86. Lincoln YS, Guba EG. Naturalistic inquiry. Newbury Park, CA: Sage Publications, Inc. 1985

87. Feltovich PJ, Johnson PE, Moller JH, Swanson DB. The role and development of medical knowledge in diagnostic expertise. In Clancey WJ, Shortliffe EH, (eds). Readings in medical artificial intelligence Reading. (eds)MA: Addison-Wesley.1984. pp. 275-319.

88. Yielder J. An integrated model of professional expertise and its implications for higher education. Internat J Life Educ 2004;23:60-80.

89. King G, Currie M, Bartlett DJ, Gilpin M, Willoughby C, Tucker MA, Strachan D, Baxter D. The development of expertise in pediatric rehabilitation therapists: changes in approach, self-knowledge, and use of enabling and customizing strategies. Dev Neurorehabil 2007;10: 223-240.

90. King G, Currie M, Bartlett DJ, Strachan D, Tucker MA, Willoughby C. The development of expertise in paediatric rehabilitation therapists: the roles of motivation, openness to experience, and types of caseload experience. Aust Occup Ther J 2008;55:108-122.

91. Miles A, Grey JE, Polychronis A, Price N, Melchiorri C. Developments in the evidence-based health care debate - 2004. J Eval Clin Pract 2004;10:129-142.

92. Korner-Bitensky N, Desrosiers J, Rochette A. A national survey of occupational therapists' practices related to participation post-stroke. J Rehabil Med 2008;40:291-297.

93. Menon-Nair A, Korner-Bitensky N, Ogourtsova T. Occupational therapists' identification, assessment, and treatment of unilateral spatial neglect during stroke rehabilitation in Canada. Stroke 2007; 38:2556.

94. Menon A, Korner-Bitensky N, Kastner M, McKibbon KA, Straus S. Strategies for rehabilitation professionals to move evidencebased knowledge into practice: a systematic review. J Rehabil Med 2009;41:1024-1032.

95. Green LA, Gorenflo DW, Wyszewianski L; Michigan Consortium for Family Practice Research. Validating an instrument for selecting interventions to change physician practice patterns: a Michigan Consortium for Family Practice Research study. J Fam Pract 2002;51:938-942.

96. Korner-Bitensky N, Menon-Nair A, Thomas A, Boutin E, Arafah AM. Practice style traits: do they help explain practice behaviours of stroke rehabilitation professionals? J Rehabil Med 2007;39:685-692. 


\section{Appendix A: Stimulus Vignette}

Mrs P. is a 78-year-old woman widowed for 5 years. Her past medical history includes, hypertension, diabetes, bilateral cataracts, osteoarthritis in her knees and spine and vertigo. She also has a history of urinary track infections and pneumonia. She lives alone in a 2-storey single family house which she has owned for 35 years. Her bedroom is on the second floor which she accesses with 17 steps and a railing (13 steps, a landing and 4 more steps). There are no steps outside the home. The main bathroom with the bath and shower are on the second floor. There is a powder room with a toilet and sink on the main floor. Mrs P. has a son who lives in Toronto and a daughter who lives 20 minutes away but is burdened with a busy job and who helps to care for her frail, live-in father-in law. The daughter also occasionally baby sits her 6-month old grandson. Mrs P. has a neighbor that she has known for many years but with whom she does not have any significant contact. She does not have any other friends or social network. Her income is limited with a modest old age pension and small savings which are running out. Mrs P. worked as a clerical assistant for a window manufacturer for 13 years but stopped working to raise her children and never returned to work. When her children left home she began volunteering in a nearby community center. She volunteered there for 25 years. She enjoys sewing, playing cards, reading, knitting and watching television. She went to church every Sunday morning until about 3 years ago. In the last 3 years she has become less active: she stopped going to church and has been more homebound. When asked why she does not go out as much she says: I'm just not up to it".

Mrs P. fell getting out of bed one night to go the bathroom. She could not move much and remained on the floor for almost 24 hours. Eventually she crawled to the phone and called her daughter who in turn called the ambulance. When asked what happened she told the ambulance technician: "I don't know, I suddenly found myself on the floor". She was taken to the emergency where an X-Ray revealed a right hip fracture (intertrochanteric neck of the femur). Four days after her fall she had a hemiarthroplasty (partial right hip replacement). The surgery was successful and 5 days later she was transferred to a rehabilitation hospital with the following restrictions: 90 degrees right hip flexion, no hip internal rotation and no hip adduction. She is permitted to weight bear fully. The first day at the rehabilitation hospital she was seen by an OT for a wheelchair assessment and PT for evaluation of transfers and for the loan of a walking aid. On the second day, she was seen by OT for an initial interview and complete ADL assessment using the FIM (Functional Independence Measure). The results of the initial interview and ADL assessment are:

- This is her first documented fall but she has admitted to several "near falls" without injury

- There are mild cognitive problems (temporal orientation and short term memory) which are observed from talking with her and observing her during dressing and transfers,
- She requires close supervision for chair and toilet transfers and assistance for shower and bed transfers,

- She requires moderate assistance with lower body dressing, use of a walker and close supervision for ambulation for short distances and requires moderate assistance to wash her lower body in the shower in a sitting position

- She requires frequent reminders to respect her restrictions; She follows instructions inconsistently,

- She has skin redness on the buttocks and swelling in the right leg,

- She complains of pain in the right hip upon movement (7/10 on the Visual Analog Scale)

- She is unable to maintain adequate positioning in bed or to change positions in bed,

- She has good static balance but precarious unsupported standing balance when she stands to pull up her undergarments and trousers.

- She has poor endurance (fatigues after walking 5 to 7 meters).

The treatment plan in OT included: 1) a formal screening of her mental status (Mini Mental Status Examination: 24/30 - borderline score), 2) providing technical aids for dressing and education on their use, 3) teaching and practice of safe transfers and bed mobility, 4) meeting with daughter to discuss patient's pre-fall situation, 5) practice of functional mobility with walker, 6) endurance exercises, 7) self-medication program, 8) evaluation of Instrumental Activities of Daily Living (IADL) 9) referral to social work. Mrs P has now been in rehabilitation for 4 weeks. The team is discussing her discharge which is scheduled to be in 2 weeks. Mrs P's clinical profile at discharge is as follows:

- She can dress and undress using a long-handled reacher, shoehorn, sock aid and elastic laces,

- She can sponge bathe at the sink in sitting and needs help to get in the bathtub using grab bars to sit on bath chair.

- She transfers out of bed independently; can transfer to the car independently and can transfer to the toilet independently using a raised toilet seat. She needs a commode (at her bed side) for night time.

- She can prepare breakfast and reheat meals but needs assistance for meal preparation.

- She walks with a walker independently indoors and requires supervision for mobility outdoors.

- She can go up and down the stairs with a cane, 1 rail and close supervision.

- She can manage her meds with a dossette box (pill box)

- Mini Mental score: 27/30 considered within normal limits Mrs P. will be discharged home with the following recommendations: 1) temporarily move her bed to the main floor for easier access to the powder room and kitchen, 2) referral to CLSC for bathing and home safety evaluation, 3) referral to Meal on Wheels, 4) information on lifeline service, 5) referral to adapted transport, 6) purchase of adaptive equipment for bathroom (grab bars, bath seat and raised toilet seat) for her home (these have been ordered). She has already purchased a long shoe horn, a sock aid, elastic laces and a tray for her walker. 7) Her daughter will assist with groceries and laundry 


\section{A. Thomas et al.}

and she will have help for housecleaning once very 2 weeks. There are 2 weeks left prior to her discharge and the team is considering the recommendation that Mrs P. take part in the hospital's fall prevention program. Mrs P. and her daughter have been informed that you are thinking of having her take part in the Fall Prevention Program. They ask you to explain how this program will be of additional benefit for her, given her exposure to Occupational and Physical Therapies on the ward. How would you respond and how would you justify your response? 